\title{
EFFECT OF OSMOTIC DEHYDRATION IN THE APPLE (Pyrus malus) VARIETIES GALA, GOLD AND FUJI
}

\begin{abstract}
C. P. Moura ${ }^{a}$, ABSTRACT
M. L. Masson ${ }^{a}$

and C. I. Yamamoto ${ }^{\mathrm{a}}$

${ }^{a}$ Universidade Federal do Paraná Departamento de Engenharia Química Bairro Jardim das Américas CP. 19011, Curitiba, Paraná, Brasil mouracp@ufpr.br

Some raw material characteristics were evaluated in three apple varieties Gala, Gold and Fuji. The study was undertaken to collect information in order to identify the effects of initial tissue properties on mass transport phenomena in general, and osmotic processing responses in particular. The apples, obtained from the local market, were washed, peeled and cut into $10 \mathrm{~mm}$ cube. After this, the samples were dehydrated in sugar osmotic solution $(50 \% \mathrm{w} / \mathrm{w})$ at $30^{\circ} \mathrm{C}$ and $110 \mathrm{rpm}$ of agitation. The ratio of foodstuff to osmotic solution was greater than 1:20. The mass transfer kinetics was measured in intervals of 20 minutes during 3 hours. The mass transfer kinetics of the different apple varieties has presented different behavior during the osmotic dehydration. The apples vs. Gala have presented the highest water loss and solid gain. The vs. Gold presented a lower tendency to solid uptake.

Keywords: apple variety, osmotic dehydration, mass transfer
\end{abstract}

\section{NOMENCLATURE}

\author{
d.m. dry matter \\ g mass, $\mathrm{g}$ \\ gi inicial mass, $g$ \\ min minutes \\ vs variety
}

\section{INTRODUCTION}

Osmotic dehydration is a viable process for the partial removal of water from cellular material, such as fruits and vegetable, without a phase change and is often applied as a pretreatment process. This process reduces the physical, chemical and biological changes during drying at high temperature (Kowalska and Lenart, 2000).

The osmotic dehydration consists of food immersion in hypertonic solution (e.g. salt, sugar, sorbitol, glycol). The concentration difference drives water from the food to the solution in order to dilute the hypertonic solution. The cellular structure of the food acts as a semi-permeable membrane, which is not completely selective, resulting in two counter-currents of mass transfer: diffusion of water from the food to the solution and diffusion of solid from the osmotic solution to the food (Raoult-Wack, 1994). In the beginning of the osmotic dehydration, the highest rate of mass transfer is observed due to the difference of osmotic pressure between the solution and the cellular wall of the food and to the small mass transfer resistance (Nieto et al., 2004; Barbosa-Cánovas and Vega-Market, 2000).
The mass transfer rate during the osmotic pretreatment as well as the changes in the chemical composition of the food according to Rastogi et al. (2002) and Lerici et al. (1985), depend on the temperature of the solution, nature and molecular weight of the dehydration agent, concentration of the solution; ratio between solution and food, geometry and cellular structure of the food. Chiralt and Talens (2005), relating that the properties of the final products are depend on the product characteristics, such as cultivars, variety, ripeness degree and the tissue microstructure (cell packaging and porosity, membrane permeability, etc).

The apple is a fruit of the tree Pyrus Malus, with thin and impermeable skin, sweet and sour flavor, acid or farinaceous and homogeneous pulp, that depends on the species. In general, it can be harvested during the whole year (Pros, 1980). Apples are also rich in water content, approximately $85 \%(\mathrm{w} / \mathrm{w})$. According to Cruz (1990) it is possible to dehydrate apples because the sensorial attributes such as good texture, high sugar content and acidity are maintained.

This study was undertaken to verify the influence of the different tissues of apples variety Gala, Gold and Fuji on the mass transfers during the osmotic pretreatment

\section{EXPERIMENTS}

The apples vs. Gala, Gold and Fuji were acquired in the local market, being washed, peeled and cut in cubes of $1 \mathrm{~cm}$. Commercial sucrose was 
used to prepare the osmotic solution at a concentration of $50 \%(\mathrm{p} / \mathrm{p})$, under stirring (110 rpm) and at a constant temperature of $30^{\circ} \mathrm{C}$. The ratio between solution and sample was 20:1 to avoid significant dilution of the medium and subsequent decrease of the (osmotic) driving force during the process (Lazaridis et al., 1996). Samples were collected in intervals of 20 minutes for 3 hours of dehydration. The samples were weighed and the total dry weight was determined at $105^{\circ} \mathrm{C}$ for 24 hours. The experiments were repeated twice.

The measured values were expressed as:

- Weight reduction of the sample, in $g$ per $g$ of initial dry matter, g/gi.d.m.

- Water loss, in g of water per g of initial dry matter, g water/gi.d.m.

- Solid gain, in g of dry matter per g of initial dry matter, g/gi.d.m.

- Rate of solid gain, in g per g of initial dry matter per minute, g/gi.d.m.min.

- Rate of weight reduction, in g per g of initial dry matter per minute, g/gi.d.m.min

- Rate of water loss in $g$ of water per $g$ of initial dry matter per minute, g water/gi.d.m.min.

\section{RESULTS AND DISCUSSION}

The influence of the apples vs. Gala, Gold and Fuji on the weight reduction during the osmotic dehydration is observed in Fig. 1. The weight reduction increases with time.

The weight reduction of the apple vs. Gold was $70 \%$ of the total weight on the first hour of pretreatment. In the apples vs. Gala and Fuji the weight reduction was approximately $50 \%$ of the total weight at the same time. But, in the end of the pretreatment the vs. Gala showed the highest weight reduction.

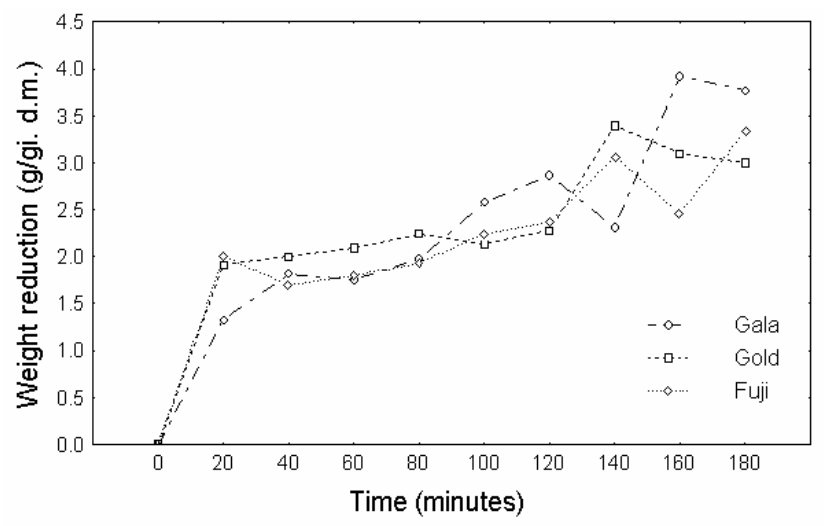

Figure 1. Weight reduction with time for the apple varieties.
The solid gain is presented in Fig. 2, showing a tendency to stabilize after 60 minutes of dehydration. Higher solid transfer happened in the first minutes. The vs. Gold has presented the lowest gain of solids 0.740 g.d.m./gi.d.m. The values of the vs. Gala and Fuji were both approximately 0.9 g.d.m./gi.d.m. of solid gain. Mavroudis et al., (2004), evaluated three apple varieties cultivated in Southern Sweden, namely Kim, Mutsu and Jonagold. The mass transport phenomena were studied during the osmotic dehydration processing and the tissue effects of the apples varieties properties was undertaken. They verified the significance of the initial tissue structure in the response to osmotic processing and the Jonagold apple variety had presented the lower solid gain than the others varieties. Kowalska and Lenart, (2000) when dehydrated vegetables had verified the influence of the kind of plant tissue.

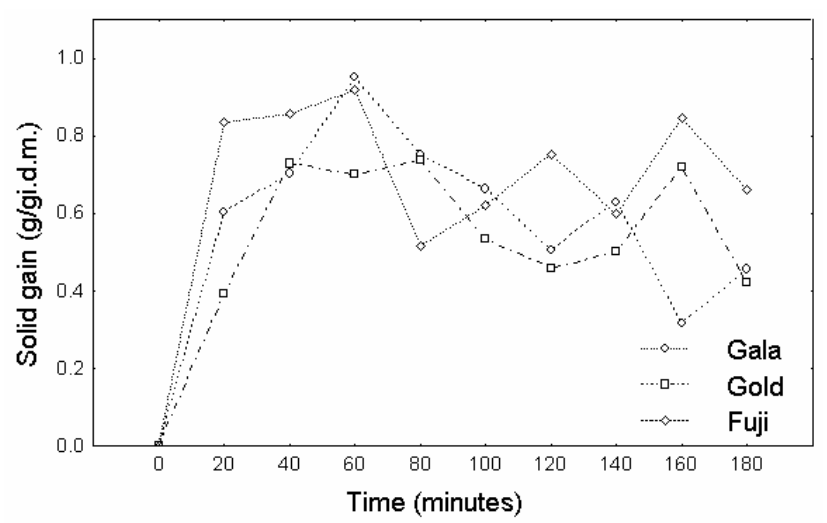

Figure 2. Solid gain with time for the apple varieties.

The water loss (Fig. 3) during the dehydration is calculated by the sum of the weight reduction and solid gain during the pretreatment. This important variable shows the same behavior for all varieties, i.e. a tendency to lose water with time. The water loss values on the initial of the process was higher for the vs. Gold but along the process this variety had had presented the lower tendency to increase the water loss the vs. Gala and Fuji.

The weight reduction rate was higher in the first minutes of the process for all varieties, as shown in Fig. 4. The vs. Gold and Fuji obtained the highest rate in the first 20 minutes. After that, these varieties presented an ascending rate in the next 60 minutes. 


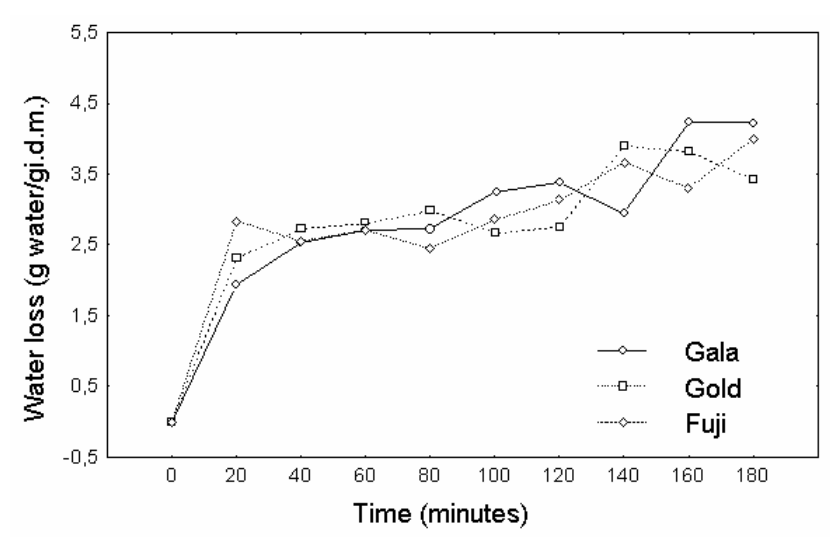

Figure 3. Water loss during dehydration.

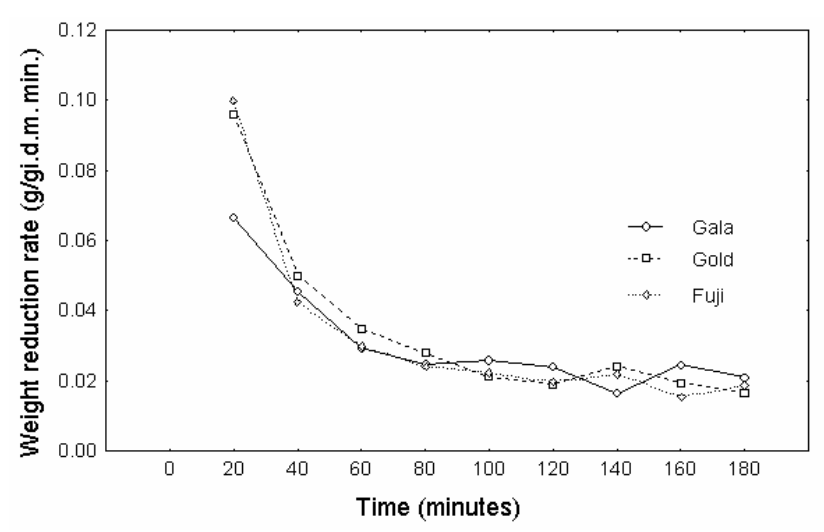

Figure 4. Weight reduction rate for the apple varieties.

The solid gain rate was higher in the first 20 minutes of the process. The apple vs. Gold presented the lowest solid gain rate. The vs. Fuji presented the highest rate (Fig. 5). The water loss rate was higher in the vs. Fuji followed of the vs. Gold (Fig. 6).

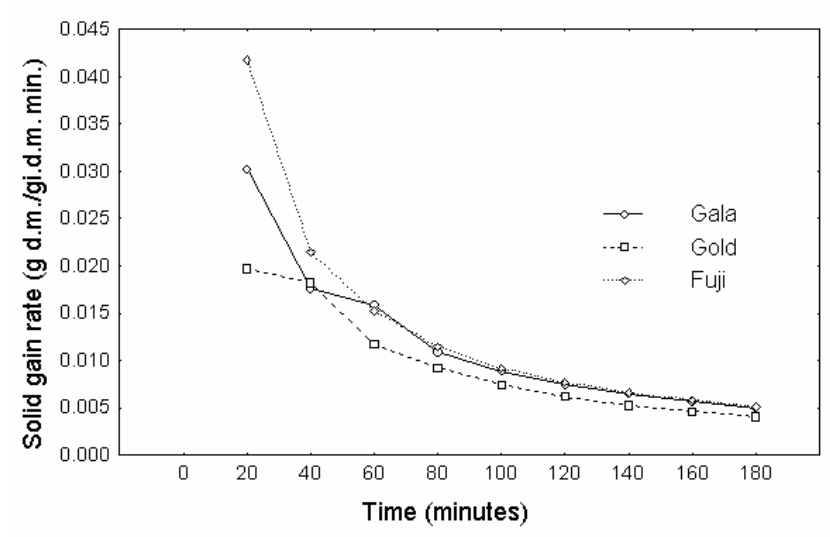

Figure 5. Solid gain rate for the apple varieties.

The aim of osmotic dehydration is to remove water from plant tissue in such a way that the penetration of osmoactive substance from solution to the material is severely reduced. Figure 7 shows that the aim of this process was completely achieved as was studied by Kowalska and Lenart (2001). The water loss and solid gain rate was higher in the first 10 minutes of the process. The water loss rate was 5 to 10 times higher than the others.

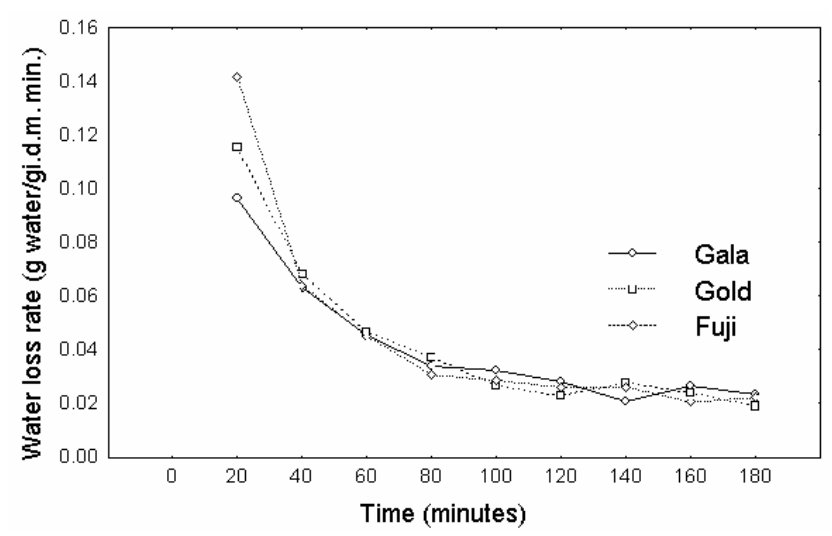

Figure 6. Water loss rate for the apple varieties.

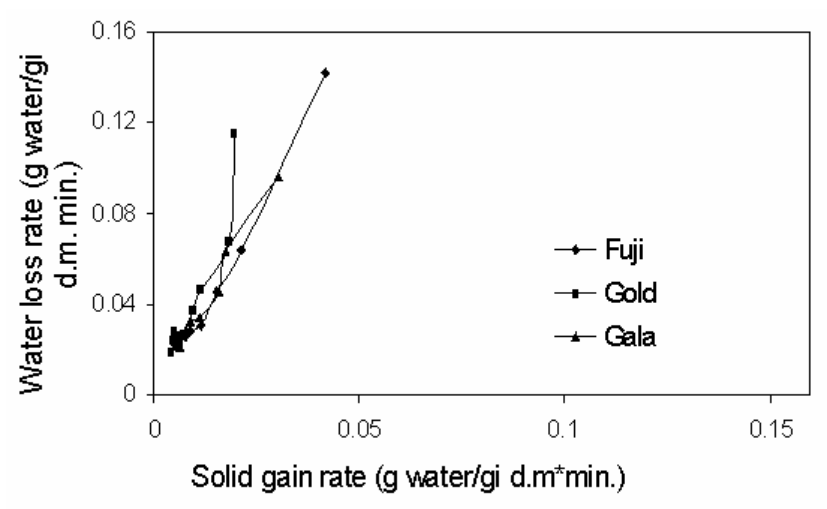

Figure 7. Water loss rate in relation weight reduction rate.

\section{CONCLUSIONS}

The kind of plant tissue of the apples varieties Gala, Gold and Fuji showed to have influence on the mass transfer process phenomenon during the osmotic dehydration. The apple vs. Gala presented the highest water loss and solid gain. The vs. Gold presented the smallest solid gain.

\section{REFERENCES}

Barbosa-Cánovas, G., Vega-Mercado, H., 2000, Desidratación de alimentos. Zaragoza Editorial Acribia S.A. (in Spanish)

Chiralt, A., Talens, P., 2005, Physical and chemical changes induced by osmotic dehydration 
in plant tissues. Journal of Food Engineering, Vol. 67, pp. 167-177.

Cruz, G. A., 1990, Desidratação de alimentos. 2ed. Editora Globo.

Kowalska, H., Lenart, A., 2001, Mass exchange during osmotic pretreatment of vegetables, Journal of Food Engineering, Vol. 49, pp. 137-140.

Lazarides, H. N.; Katsanidis, E.; Nickolaidis, A. (1995). Mass transfer kinectics osmotic preconcentration aiming at minimal solid uptake. Journal of Food Engineering. Vol. 25, pp. 151-166.

Lerici, C. R., Pinnavaia, G., Dalla Rosa, M., Bartolucci, L., 1985, Osmotic dehydration of fruit: Influence of osmotic agents on drying behavior and product quality, Journal of Food Technology, Vol.18, pp. 667-685.

Nieto A. B., Salvatori, D. M., Castro, M. A., Alzamora, S. M., 2004, Structural changes in apple tissue during glucose and sucrose osmotic dehydration: Shrinkage, porosity, density and microscopic features, Journal of Food Engineering, Vol. 61, pp. 269-278.

Pros, J. S., 1980, A maçã e a saúde, Editorial Presença. (in Portuguese)

Raoult-Wack, A. L., 1994, Recent advances in the osmotic dehydration of foods, Food Science \& Technology, Vol. 5, pp. 255-260.

Rastogi, N. K.; Raghavarao, K. S. M. S., Niranjan, K., Knorr, D., 2002, Recent developments in osmotic dehydration: Methods to enhance mass transfer. Trends in Food Science and Technology, Vol. 13, pp. 48-59.

Mavroudis, N. E., Dejmek, P., Sjöholm I., 2004, Studies on some raw material characteristics in different Swedish apple varieties. Journal of Food Engineering, Vol. 62, pp. 121-129. 